\title{
Optimal Conditions for Isolation of Nanocrystalline Cellulose Particles
}

\author{
Michael Ioelovich
}

Designer Energy Co., Rehovot, 76100, Israel

\begin{abstract}
Nanocrystalline cellulose particles are new class of cellulose materials that can find the wide application in various technical areas, biotechnology and medicine. The nanoparticles are usually made by treatment or initial cellulose samples with concentrated sulfuric acid (SA) at various temperatures and following mechanical or ultrasound disintegration. Unfortunately, conditions of existing methods for preparation of nanocellulose are multifarious and give both crystalline and amorphous nanoparticles. Therefore in this paper the optimal conditions for obtaining just of nanocrystalline cellulose particles (NCP) have been studied. The experiment showed that isolation of NCP is carried out in narrow interval of the acid concentration: from 50 to about $61 \mathrm{wt}$ \%. If concentration of SA is less than $50 \mathrm{wt}$. \% then micro-scale particles are isolated. On the other hand, if concentration of SA is higher than $63 \mathrm{wt} . \%$ the cellulose completely dissolves, and as a result instead of nanocrystalline the amorphous particles are formed with decreased yield. In the range of the acid concentration from 55 to 61 wt. \%, a low decrystallization of the initial cellulose is taken place that contributes to forming of rod-like nanocrystalline cellulose particles. The following optimal conditions of the acidic treatment for isolation of NCP were proposed: concentration of sulfuric acid 57-60 wt. \%, acid to cellulose ratio 8-10, temperature $45-55^{\circ} \mathrm{C}$, time $40-60 \mathrm{~min}$. These optimal conditions in combination with the high-power disintegration permit obtaining the rod-like nanocrystalline cellulose particles $(150-200 \times 10-20 \mathrm{~nm})$ with the increased yield (70-75\%).
\end{abstract}

Keywords Cellulose, Nanoparticles, Nanocrystallites, Preparation, Optimal Conditions

\section{Introduction}

Nanocrystalline cellulose particles (NCP) are new class of cellulose materials that are characterized by increased crystallinity, high aspect ratio, developed specific surface, improved dispersion ability, biodegradability, and stability to aggressive medium, increased temperatures and proteolytic enzymes[1-3]. Due to these features, NCP can be used as a high-quality reinforcing filler for polymers and biodegradable materials, strengthening additive for papers, thickener for dispersions, as well as drug carrier and implant, etc.[4-12]. These particles can be made by treatment of initial cellulose samples with concentrated sulfuric acid (SA) at various temperatures and following mechanical or ultrasound disintegration of the acid-treated cellulose in water[2, 13-21]. For disintegration step the high-pressure homogenizers, high-shear mills or ultrasound disintegrators giving an increased local pressure $\mathrm{P} \geq 50 \mathrm{MPa}$ are used.

Details of NCP-generation are not enough clear. Its mechanism is explained usually by selective acid hydrolysis of disordered (amorphous) domains of cellulose nano-fibrils,

* Corresponding author:

bd895892@zahav.net.il (Michael Ioelovich)

Published online at http://journal.sapub.org/nn

Copyright (C) 2012 Scientific \& Academic Publishing. All Rights Reserved whereas more resistant nanocrystallites remained intact and can be isolated in a form of rod-like particles[2]. However, this mechanism doesn't explain why the nano-size particles cannot be isolated even after intensive mechanical disintegration of cellulose hydrolysed by diluted acids up to level-off DP[13]. The probable cause of this phenomenon is that crystallites of real cellulose samples are joined together in lateral detections by means of strong crystalline contacts. The enough concentrated acid is required to break these strong contacts and release free nanocrystallites. However, when cellulose is hydrolysed by diluted acid, then strong inter-crystallite contacts remained intact and instead of nano-particles the micron-size crystalline aggregates of so called microcrystalline cellulose are formed[22].

Initial celluloses of various origins such as tunicate, cotton, wood pulp, ramie, hemp, flax, sisal, microcrystalline cellulose and some others are used to prepare $\mathrm{NCP}[2,13-21]$. To obtain the cellulose nanoparticles the concentration of sulfuric acid in hydrolysis reactions can vary from 44 to $70 \mathrm{wt}$. \%; the temperature can range from 25 to $70^{\circ} \mathrm{C}$ and the hydrolysis time can be from $30 \mathrm{~min}$ to overnight depending on the temperature[2, 14-21].

To prepare NCP the following typical treatment conditions of the initial cellulose are proposed: concentration of SA about $63-65$ wt. $\%$, temperature $40-50^{\circ} \mathrm{C}$, time $1-2 \mathrm{~h}[2,17]$. However, other researchers disclosed that treatment of the 
initial cellulose with $63-65 \%$ wt. SA is accompanied by its swelling and dissolving[23, 24]. When the acidic solution of cellulose is diluted with water the soluble cellulose is regenerated and precipitated in a form of amorphous flocks. After disintegration of these flocks in water medium, the low-molecular amorphous particles are isolated. An additional problem is an accelerated hydrolysis of cellulose macromolecules in the acidic solution that leads to decrease in yield of nanoparticles. So, nanoparticles prepared by hydrolysis of cellulose with highly concentrated acids $(>63$ wt. \%) were amorphous and had low DP about 40[23, 24].

Thus, the more detailed investigations are required to determine optimal conditions for isolation just the nanocrystalline cellulose particles.

\section{Experimental}

\subsection{Material}

Initial cellulose material was microcrystalline cellulose (MCC) Avicel PH-301 made of FMC BioPolymer Co. This MCC type has average particles size of $50 \mu \mathrm{m}$ and $\mathrm{DP}=170$.

\subsection{Preparation of Nanoparticles}

The initial MCC sample was mixed with water in a lab glass, and then 76-78 wt. \% sulfuric acid (SA) was slowly added at cooling to obtain the required final concentration of SA from 50 to 67 wt. \% and acid/cellulose ratio (ACR) from 5 to 20 . The glass was placed into water bath having temperature from 40 to $60^{\circ} \mathrm{C}$ and heated at stirring for $30 \mathrm{~min}$ to $3 \mathrm{~h}$. After acidic treatment contents of the glass was poured out into tenfold volume of cold water at stirring. Cellulose sediment was separated from liquid phase by centrifugation at the acceleration of $3200 \mathrm{~g}$ for $10 \mathrm{~min}$; washed with water, $5 \%$ sodium bicarbonate and finally with distillated water to $\mathrm{pH}$ about 6 , separating from the liquid phase at the each washing by centrifugation. Then the washed cellulose sediment was diluted with distillated water up to solid concentration 2-3 wt. \% and disintegrated by high-pressure homogenizer APV-2000 at pressure $100 \mathrm{MPa}$.

To obtain the dry nano-powder the following procedure was carried out. The water dispersion of nanoparticles was evaporated in vacuum at $80^{\circ} \mathrm{C}$ to about $10-15 \%$ solid content, washed with absolute ethanol, acetone and hexane, separating from the solvents at the each washing by centrifugation, and finally dried at $50^{\circ} \mathrm{C}$ up to constant weight.

\subsection{Method of Laser Light Diffraction}

Average length of particles $\left(\mathrm{L}_{\mathrm{a}}\right)$ in water dispersions was determined by laser diffraction method using "Mastersizer-3000" apparatus of Malvern Co.

\subsection{Method of Scanning Electron Microscopy}

Shape and size of particles were investigated by SEM "Hitachi S-4700". The diluted dispersion of cellulose nanoparticles was subjected to ultrasonic treatment for $5 \mathrm{~min}$.
A drop of the diluted dispersion was applied onto a substrate, dried and the dry sample was coated with a thin layer of gold. Then the sample was placed in the microscope, evacuated and electronic image of particles was obtained.

\subsection{Method of XRD}

A Rigaku-Ultima Plus diffractometer $\left(\mathrm{CuK}_{\alpha}\right.$ - radiation, $\lambda=0.15418 \mathrm{~nm}$ ) was used for X-ray investigations. Diffractograms of dry powders were recorded in the $\varphi=2 \Theta$ angle range from 5 to $80^{\circ}$. After recording of the diffractograms, the background was separated, and selected X-ray patterns were corrected and normalized. Then diffraction intensities from crystalline and non-crystalline regions were separated by a computerized method. Crystallinity degree $(X)$ of the cellulose samples was calculated according to equation:

$$
X=100 \% \int J_{c} d \varphi / \int J_{0} d \varphi
$$

where $J_{c}$ and $J_{o}$ are the corrected and normalized intensities of diffractions from the crystalline part and whole sample respectively.

\subsection{Determination of Cellulose Solubility in SA}

About $2 \mathrm{~g}$ of initial MCC were mixed with water in a lab glass and then 75 wt. \% sulfuric acid was slowly added at cooling to obtain the required final concentration of SA from 50 to 67 wt. $\%$ and ACR about 15. The glass was placed into water bath having temperature $50^{\circ} \mathrm{C}$ and heated at stirring for $2 \mathrm{~h}$. The insoluble residual part of the cellulose was separated from the acid by centrifugation at acceleration rate $3200 \mathrm{~g}$ for $10 \mathrm{~min}$ and then washed with water, 5 wt. \% sodium bicarbonate, distillated water up to neutral $\mathrm{pH}$-value and absolute ethanol separating from the liquid phase at the each washing by centrifugation. Finally the cellulose residue was dried at $105^{\circ} \mathrm{C}$ up to constant weight. Solubility of cellulose (S) was calculated by the equation:

$$
\mathrm{S}=100 \%\left[1-\left(\mathrm{W} / \mathrm{W}_{\mathrm{o}}\right)\right]
$$

where $W_{o}$ is initial weight of the sample, $W$ is weight of insoluble part of the sample.

\subsection{Determination of Average Degree of Polymerization}

The average degree of polymerization (DP) was measured by the viscosity method using diluted solutions of cellulose powders in Cadoxen.

\section{Results and Discussion}

The effect of sulfuric acid concentration on structure and size of obtained cellulose particles was preliminary studied at $50^{\circ} \mathrm{C}$, ACR 15 for $2 \mathrm{~h}$; then the acid-treated cellulose was washed up to $\mathrm{pH}$ about 6 , diluted with water up to $2.5 \mathrm{wt}$. \% solid content and undergone mechanical disintegration.

According to XRD investigations, in the range of SA concentration from 55 to $62 \mathrm{wt}$ \% the obtained particles retain 
crystallinity that is similar to the crystallinity of the initial MCC sample. On the other hand, when SA concentration is more than 63 wt. \% then MCC sample dissolves in the sulfuric acid; as a result highly amorphous low crystalline particles are formed (Fig. 1).

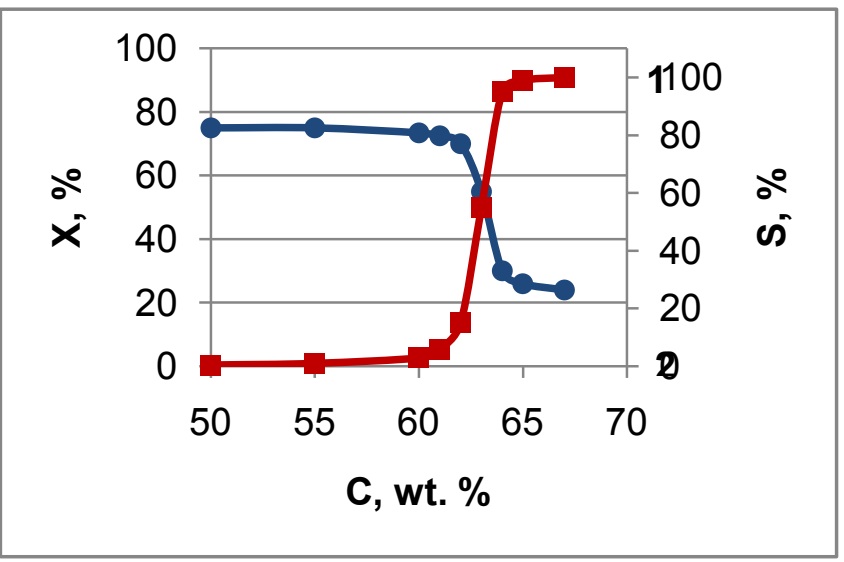

Figure 1. Dependence of cellulose solubility (1) and crystallinity degree (2) of isolated particles on concentration of sulfuric acid

The dissolving process is accompanied by essential falling in $D P$-value and yield of the particles due to hydrolysis of cellulose macromolecules in the acidic solution (Fig. 2).

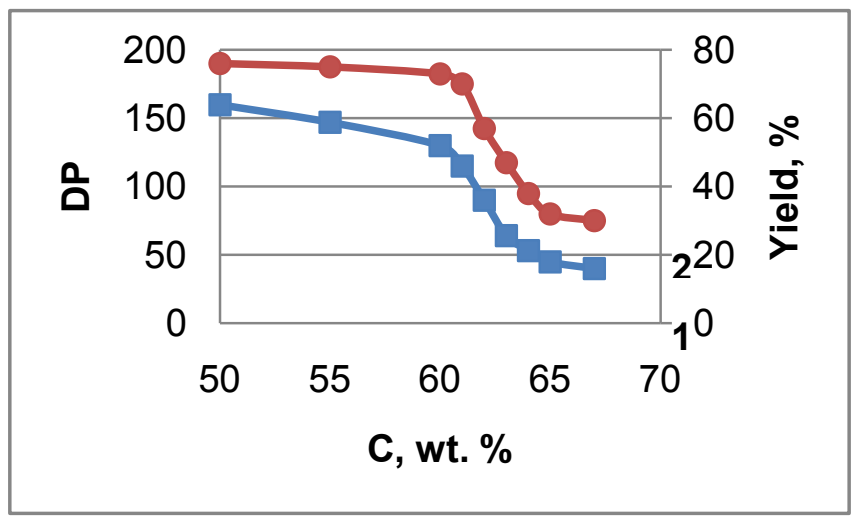

Figure 2. Dependence of average DP (1) and yield (2) of isolated particles on concentration of sulfuric acid

Investigations show that after treatment of initial cellulose with $<50$ wt. $\%$ sulfuric acid, e.g. 45 wt. $\%$, the micro-scale particles only can be obtained (Fig. 3).

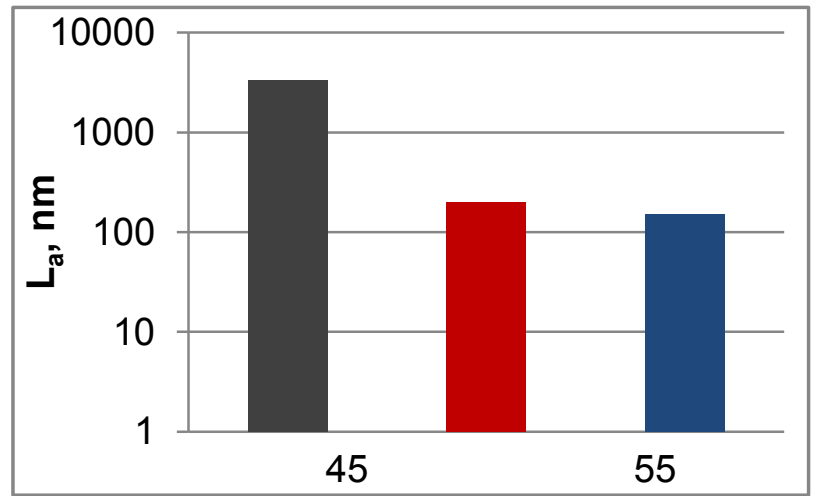

Figure 3. Average length of particles formed after treatment of initial sample with sulfuric acid and the following disintegration
To obtain the nano-scale particles the concentration of SA should be higher than $50 \mathrm{wt}$. \%. The nanocrystalline particles isolated by treatment of initial MCC sample with about 60 wt. \% SA, have a rod-like shape of about 150-200 x 10-20 nm (Fig. 4). On the other hand, if concentration of SA is $>63$ wt. \%, then amorphous ellipsoidal nanoparticles with wide size distribution (from 50 to $300 \mathrm{~nm}$ ) are observed (Fig. 5).

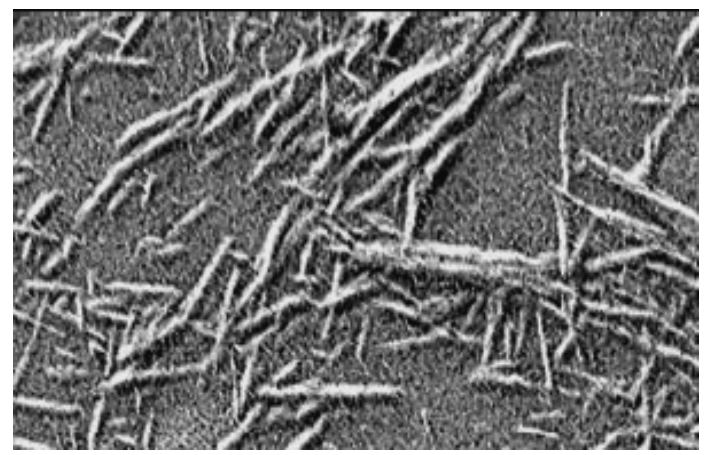

Figure 4. SEM image of rod-like nanocrystalline cellulose particles

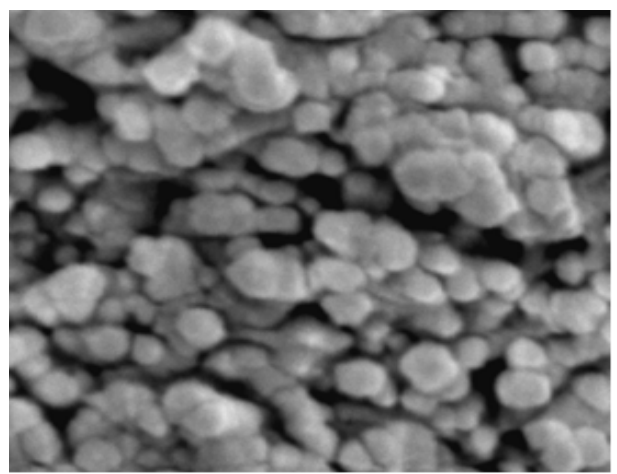

Figure 5. SEM image of amorphous ellipsoidal cellulose nanoparticles

It can be noted here that in contrast to high-molecular cellulose fibers (e.g. cotton, flax, wood cellulose, etc.) that are required to hydrolyse obligatory up to level-off DP in order to prepare nanoparticles, the initial MCC sample is already hydrolysed cellulose consisting of nanocrystalline aggregates. Therefore main aim of MCC treatment with the enough concentrated sulfuric acid is erosion of contacts between nano-crystalline aggregates and introduction of negative-charged sulfate groups contributing to breakdown these aggregates at the following high-power disintegration in water medium. If the acid concentration is low too $(<50 \mathrm{wt}$. \%), then nano-crystalline aggregates are remained intact and nano-scale particles cannot be formed. On the other hand, when the concentration of SA is much high ( $>63 \mathrm{wt} . \%)$, then MCC fully dissolves; moreover the dissolving process is accompanied by depolymerization of cellulose macromolecules in the hot acid and falling of the yield. After diluting of the solution with water, flocks of the low-molecular amorphous cellulose are precipitated. Under the high-power disintegration in water medium these flocks turn into amorphous nanoparticles.

As follows from the experiment, isolation just of the 
rod-like nanocrystalline cellulose particles is carried out in the narrow range of the acid concentration, from 55 to about 61 wt. \%.

If temperature of acidic treatment is low $\left(25-30^{\circ} \mathrm{C}\right)$ then sulfonation process requires long time too. On the other hand, if temperature is higher than $60^{\circ} \mathrm{C}$ darkening of cellulose nanoparticles is taken place due to their dehydration and carbonization. Therefore, the optimal temperature of the acidic treatment is in the range of $45-55^{\circ} \mathrm{C}$.

At low $\mathrm{ACR} \leq 5$ the treatment process is not enough uniform that leads to wide distribution in particles sizes. If ACR is $\geq 20$, then homogenous acidic treatment is performed, but used volume of the acid is high too. The optimal ACR is in the range $8-10$.

Thus, the following optimal conditions of the acidic treatment were found: concentration of sulfuric acid 57-60 wt. \%, temperature $45-55^{\circ} \mathrm{C}$, time $40-60 \mathrm{~min}$. Besides, an additional high-power mechanical or ultrasound treatment should be performed to disintegrate aggregates and release the free nanoparticles. These conditions permit isolation from initial MCC sample the rod-like nanocrystalline particles (nano-whiskers) that are characterized by increased crystallinity degree (75-77\%) and high aspect ratio (10-20) (Table 1).

Table 1. Main characteristics of the nanocrystalline cellulose particles

\begin{tabular}{|c|c|}
\hline Characteristics & Value \\
\hline Average particle length, $\mathrm{nm}$ & $150-200$ \\
\hline Average particle width, $\mathrm{nm}$ & $10-20$ \\
\hline Aspect ratio & $10-20$ \\
\hline Degree of polymerization & $120-140$ \\
\hline Crystallinity degree, $\%$ & $75-77$ \\
\hline Type of crystalline polymorph & $\mathrm{C} 1$ \\
\hline
\end{tabular}

\section{Conclusions}

The effect of sulfuric acid (SA) concentration, acid/cellulose ratio (ACR), temperature and treatment time, as well as disintegration conditions had been studied to optimize preparation process of nanocrystalline cellulose particles (NCP). As is known, the initial cellulose sample - microcrystalline cellulose (MCC), contains crystalline aggregates that join together by local lateral crystalline contacts. To isolate of the free nanocrystalline particles it is required to break the crystalline contacts between adjacent nanocrystallites in the aggregates of MCC. Treatment of MCC by 57-60 wt. \% sulfuric acid causes etching of the lateral contacts and sulfonation of surface of crystallites that contribute to breakdown the aggregates and isolation of the free nanocrystalline particles at the following high-power disintegration. Use of the optimal conditions of the acidic treatment (57-60 wt. \% SA, ACR $8-10, T=45-55^{\circ} \mathrm{C} ; \mathrm{t}=40-60 \mathrm{~min}$ ) in combination with the high-power disintegration permits obtaining the nanocrystalline cellulose particles (NCP) having sizes 150-200 x 10-20 $\mathrm{nm}$ with the heightened yield $(70-75 \%)$. Due to increased aspect ratio (10-20) and high mechanical characteristics (axial Young's modulus $150 \mathrm{GPa}$, axial tensile strength about 10 $\mathrm{GPa}$ ) these NCP can be used, for example, as a reinforcing nano-filler for various composites.

If concentration of SA is higher than $63 \mathrm{wt} . \%$, then the initial cellulose sample dissolves in the acid; as a result instead of nanocrystalline particles the amorphous particles are formed with the low yield (30-40\%). The amorphous particles have poor mechanical characteristics (Young's modulus 0.5-0.7 GPa; TS=40-50 MPa) and therefore these particles cannot be suitable as a reinforcing nano-filler.

\section{REFERENCES}

[1] Lahiji, R., Xu, X., Reifenberger, R., Raman, A., Rudie, A., and Moon, R., 2010, Atomic force microscopy characterization of cellulose nanocrystals, Langmuir, 26 (6), 4480-4488.

[2] Habibi, Y., Lucia, L.A., and Rojas, O.J., 2010, Cellulose nanocrystals chemistry, self-assembly, and applications, Chem. Rev., 110, 3479-3500.

[3] Ioelovich, M., and Leykin, A., 2004, Nano-cellulose and its application, SITA, 6 (3), 17-24.

[4] Ioelovich, M, and Figovsky, O., 2010, Structure and properties of nanoparticles used in paper compositions, Mechanics Composite Materials, 46(4), 637-647.

[5] Hubbe, M.A., Rojas, O.J., Lucia, L.A., and Sain, M., 2008, Cellulosic nanocomposites - a review, Bioresources, 3 (3), 929-980.

[6] Auad, M.L., Mosiewicki, M.A., Richardson, T., Aranguren, M.I., and Marcovich, N. E., 2010, Nanocomposites made from cellulose nanocrystals and tailored segmented polyurethanes, J. Appl. Polym. Sci., 115 (2), 1215-1225.

[7] Eichhorn, S.J., Dufresne, A, Aranguren, M., Marcovich, N. E., Capadona, J.R., Rowan, S.J., Weder, C., Thielemans, W., Roman, M., Renneckar, S., Gindl, W., Veigel, S., Keckes, J., Yano, H., Abe K., Nogi, M., Nakagaito, A. N., Mangalam, A., Simonsen, J., Benight, A.S., Bismarck, A., Berglund, L.A., and Peijs, T., 2010, Review: current international research into cellulose nanofibres and nanocomposites, J. Mater. Sci., 45, $1-33$.

[8] Liu, D.G., Zhong, T.H., Chang, P. R., Li, K. F., and Wu, Q. L., 2010, Starch composites reinforced by bamboo cellulosic crystals, Biores. Technol., 101, 2529-2536.

[9] Liu, H.Y., Liu, D.G., Yao, F., and Wu, Q.L., 2010, Fabrication and properties of transparent PMMA/cellulose nanocrystals composites, Biores. Technol., 101, 5685-5692.

[10] Cao, X.D., Dong, H., and Li, C.M., 2007, New nano-composite material reinforced with flax cellulose nanocrystals in water borne polyurethane, Biomacromolecuses, 8(3), 899-904.

[11] Ioelovich, M., and Figovsky, O., 2008, Nano-cellulose as promising biocarrier, J. Adv Materials Res. 47-50, 1286-1289.

[12] Klemm, D., Schumann, D., Kramer, F., Hessler, N., Koth, D., and Sultanova, B., 2009, Nanocellulose materials - different cellulose, different functionality, Macromol. Symp. 280, 60-71.

[13] Ioelovich, M., and Leykin, A., 2006, Formation nano-structure of microcrystalline cellulose, Cell. Chem. Technol., 40 (5), 
313-317.

[14] Favier, V., Chanzy, H.,.and Cavaille, J.Y., 1995, Polymer nano-composites reinforced by cellulose whiskers, Macromolecules, 28, 6365-6367.

[15] Moran, J.I., Alvarez, V.A., Cyras, V.P., and Vazquez, A., 2008, Extraction of cellulose and preparation of nanocellulose from sisal fibers, Cellulose, 15, 149-159.

[16] Lima, M.M., and Borsali, R., 2004, Rod-like cellulose microcrystals: structure, properties and applications, Macromol. Rapid Comm., 25 (7), 771-787.

[17] Bondeson, D., Mathew, A., and Oksman, K., 2006, Optimization of the isolation of nanocrystals from microcrystalline cellulose by acid hydrolysis, Cellulose, 13 (2), 171-180.

[18] Bai, W., Holbery, J., and Li, K., 2009, A technique for production of nanocrystalline cellulose with a narrow size distribution, Cellulose 16, 455-465.
[19] Luduena, L., Fasce, D., Alvarez, V. A., and Stefani, P. M., 2011, Nanocellulose from rice husk following alkaline treatment to remove silica, Bioresources, 6(2), 1440-1453.

[20] Yu, M., Yang, R., Huang, L., Cao, X., Yang, F., and Liu, D., 2012, Preparation and characterization of bamboo nanocrystalline cellulose, Bioresources, 7(2), 1802-1812.

[21] Li, Y., and Ragauskas, A., Cellulose nano-whiskers as a reinforcing filler in polyurethanes, 2011, Advances in diverse industrial applications of nanocomposites, 3, 17-36.

[22] Battista, O.A., and Smith, P.A., 1962, Microcrystalline cellulose, Ind. Eng. Chem., 54(9), 20-24.

[23] Ono, H., Shimaya, Y., Hongo, T, and Yamane, C., 2001, New aqueous dispersion of cellulose sub-micron particles, Transaction Mater. Res. Soc. Japan, 26 (2), 569-572.

[24] Ono, H., Matsui, T., and Miyamoto, I., 2003, Cellulose dispersion US Pat. No 6,541,627. 